\title{
Molecular phylogenic location of the Plagiorchis muris (Digenea, Plagiorchiidae) based on sequences of partial 28S D1 rDNA and mitochondrial cytochrome C oxidase subunit I
}

\author{
Soo-Ung LEE ${ }^{1)}$, Sun $\mathrm{HUH}^{1) *}$ and Woon-Mok SOHN ${ }^{2)}$ \\ ${ }^{1)}$ Department of Parasitology, College of Medicine, Hallym University, Chuncheon 200-702, ${ }^{2)}$ Department of Parasitology, \\ Institute of Health Sciences, Gyeongsang National University College of Medicine, Jinju 660-751, Republic of Korea
}

\begin{abstract}
To determine the molecular phylogenic location of Plagiorchis muris, 28S D1 ribosomal DNA (rDNA) and mitochondrial cytochrome $\mathrm{C}$ oxidase subunit I $(\mathrm{mtCOI})$ were sequenced and compared with other trematodes in the family Plagiorchiidae. The 28S D1 tree of $P$. muris was found to be closely related to those of $P$. elegans and other Plagiorchis species. And, the $\mathrm{mtCO}$ tree also showed that $P$. muris is in a separate clade with genus Glypthelmins. These results support a phylogenic relationship between members of the Plagiorchiidae, as suggested by morphologic features.
\end{abstract}

Key words:trematoda, ribosomal DNA, mitochondrial DNA, phylogeny, classification

Although Plagiorchis muris was first recovered from Rattus norvegicus (Seo et al., 1981) in Korea, eleven natural cases of human infection by the genus Plagiorchis have been reported (Chai, 1991). Molecular approaches to this worm are rare since it is difficult to acquire sufficient metacercariae. Since $P$. muris is unique species of which infection in human intestine has been reported among the family Plagiorchiidae, the phylo-

- Received 12 April 2004, accepted after revision 13 May 2004.

- Sequence data from this article have been deposited with the EMBL/GeneBank Data Libraries under Accession numbers 28S rDNA sequence (AF096222), mtCOI sequence (AF096236).

- This study was supported by the research grant of Hallym University.

*Corresponding author (e-mail:shuh@.hallym.ac.kr) genic relationship with other worms in Plagiorchiidae is interesting. In the present study we determined molecular phylogenic location of $P$. muris with respect to other trematodes in the family Plagiorchiidae using the 28S $\mathrm{D} 1 \mathrm{rDNA}$ and mtCOI gene regions. It will be able to tell the consistency between morphologic and molecular phylogenic location of $P$. muris in the genus Plagiorchis.

Metacercariae of $P$. muris were obtained from dragonflies and adults were recovered from infected mouse intestines (Hong et al., 1999). Worms were kept in ethanol at $-70^{\circ} \mathrm{C}$ until assayed. Frozen worms were lyophilized and lyzed with lysis buffer containing $1 \%$ SDS, proteinase $\mathrm{K}(500 \mathrm{~g} / \mathrm{ml})$, and RNase at $37^{\circ} \mathrm{C}$ for 2-3 hrs. DNA was extracted using the phenol/chloroform method and precipitated in ethanol. The 28S D1 
rDNA and mtCOI regions were amplified by PCR using the primer sets described by Qu et al. (1988), and by Garey and Wolstenholme (1989). PCR was conducted using a mixed solution (25l) of the above extracted DNA (2.51) as a template (1-50 ng), and primers (1.01, each 10 pmole) for each genes with $\sim 1.5$ units of Taq enzyme (TAKARA Shuzo Co., LTD, Japan) in a GeneAmp PCR System 9600 (Perkin Elmer, U.S.A.). PCR amplification was conducted over 40 cycles denaturing at $95^{\circ} \mathrm{C}$ for 20 seconds, annealing at $55^{\circ} \mathrm{C}$ (28S D1 rDNA) or $48^{\circ} \mathrm{C}$ (mtCOI) for 30 seconds, extending at $72^{\circ} \mathrm{C}$ for 30 seconds), followed by a final extension of 7 minutes.

Amplified PCR products were extracted and purified using a gel extraction kit and a PCR purification kit (QIAGEN Co., Germany) and were cloned into a pT7Blue Perfectly Blunt cloning vector using T4 DNA ligase and transformed into E.coli Nova Blue competent cells, according to the supplier's protocol (Novagen Co. USA). Positive recombinant clones were picked, and grown in $2 \mathrm{ml}$ of LB broth (in the presence of $50 \mathrm{~g} / \mathrm{ml}$ ampicillin) overnight at $37^{\circ} \mathrm{C}$. The recombinant plasmid was screened using isopropylthiogalactoside (IPTG) and 5-bromo-4 chloro-3indolyl—D-galactoside (X-gal). Positive plasmid DNA was purified using a QIAprep spin plasmid kit (QIAGEN Co., Germany). DNA sequencing was performed by the dideoxy chain termination method. Cycle sequencing reactions were performed using Thermo Sequenase dye terminator sequencing pre-mix kits (Amersham Life Science Co.). PCR products were run on an ABI 373A automated DNA sequencer (Applied Biosystems model 373A, Perkin Elmer) according to the manufacturer's instructions. The each gene was sequenced in both orientations using the universal sequencing primers T7 and U19. At least two clones were sequenced per gene; additional clones were sequenced as necessary to resolve ambiguous sites.

The analyses of 28S D1 rDNA and mtCOI region sequences were determined by comparison with those of a range of other related nematodes of the family Plagiorchiidae. NCBI (National Center for Biotechnology Information, NIH, Bethesda, USA) databases were used for sequence homology analysis using
BLAST2. Multiple sequence alignments were performed using CLUSTA W program (European Bioinformatics Institute, http://www.ebi.ac.uk/ clustalw/), and the fractional GC contents of nucleic acid sequences were determined using the EMBOSS GEECEE program provided by Dr. Richard Bruskiewich (Sanger Institute, Wellcome Trust Genome Campus, Hinxton, Cambridge, CB10 1SA, UK)(http://analysis.molbiol.ox.ac.uk/pise_html/gee cee.html). Alignment gaps were treated as missing data. Other trematodes in the family Plagiorchiidae and their GenBank accession numbers used for comparative purposes in this study are listed in Tables 1 and 2. Haematoloechus longiplexus (Haematoloechidae, AY222280 for 28S rDNA) and Paragonimus macrorchis (Paragonimidae, AF159598 for mtCOI) were used as outgroups. Phylogenic analysis was performed using the Kimura 2-parameter model for distance correction; corrected for multiple substitutions (Kimura, 1980). Phylogenic trees were constructed using the Neighbor-joining algorithm (Swofford et al., 1996). In order to view these trees, we used PHYLIP version 1.6 for tree drawing using the parsimony, maximum likelihood, and distance methods.

The sizes of amplified genomic DNA fragments of 28S D1 rDNA and mtCOI were $0.3 \mathrm{~kb}$ and $0.45 \mathrm{~kb}$, respectively. The sequences length was $309 \mathrm{bp}$ for the 28S D1 rDNA gene, and 397 bp for the mtCOI gene excluding primer sequences (results not shown). The GC contents were 52\% (28S D1 rDNA) and 48\% (mtCOI) exlcuding primers. The $28 \mathrm{~S} \mathrm{D} 1 \mathrm{rDNA}$ and mtCOI coding regions were highly conserved by multiple sequence alignment without additional nucleotides, Overall nucleotide similarity between $P$. muris and other Plagiorchiidae species ranged $61.1 \% \sim 63.7 \%$ for $28 \mathrm{~S}$ D1 rDNA and $51.4 \% \sim 63.9 \%$ for mtCOI (results not shown). Several insertions, a $79 \mathrm{bp}$ insertion in P. muris 28S D1 rDNA, a 16 bp insertion in P. muris mtCOI, with gaps, 1 bp gap in P. muris $28 \mathrm{~S}$ $\mathrm{D} 1$, in the same or in different positions were detected within and between species (results not shown). The most-parsimonious tree was obtained when gaps were treated as missing data. The 28S D1 tree of $P$. muris was closely related with that of $P$. elegans and 
Table 1. Plagiorchiidae species used in this study, GenBank accession numbers for corresponding sequences, sequence lengths of the 28S D1 rDNA gene

\begin{tabular}{|c|c|c|c|c|}
\hline Species & $\begin{array}{c}\text { GenBank } \\
\text { No. }\end{array}$ & $\begin{array}{c}\text { Sequence } \\
\text { length (bp) }\end{array}$ & $\begin{array}{l}\text { Aligned sequence } \\
\text { length }(b p)^{b)}\end{array}$ & Reference \\
\hline Astiotrema monticellii & AF184253 & 1,261 & 231 & Littlewood and Bray, 2001 \\
\hline Glypthelmins californiensis & AY278052 & 1,275 & 222 & \\
\hline G. facioi & AY278046 & 1,275 & 222 & \\
\hline G. hyloreus & AY278050 & 1,274 & 222 & \\
\hline G. pennsylvaniensis & AF433676 & 1,250 & 230 & Tkach et al., 2001 \\
\hline G. quieta & AY222278 & 1,256 & 227 & Olson et al., 2003 \\
\hline G. tuxtlasensis & AY278048 & 1,274 & 223 & \\
\hline Haplometra cylindracea & AF151933 & 1,254 & 230 & Tkach et al., 2000a, 2001 \\
\hline Lecithopyge rastellus & AF151932 & 1,254 & 230 & Tkach et al., 2000a, 2001 \\
\hline Leptophallus nigrovenosus & AF151914 & 1,256 & 229 & Tkach et al., 2000a \\
\hline Macrodera longicollis & AF151913 & 1,257 & 229 & Tkach et al., 2000a \\
\hline Metaleptophallus gracillimus & AF151912 & 1,256 & 229 & Tkach et al., 2000a \\
\hline Neoglyphe locellus & AF300330 & 1,255 & 230 & \\
\hline N. sobolevi & AF300329 & 1,255 & 230 & Tkach et al., 2001 \\
\hline Paralepoderma cloacicola & AF151910 & 1,255 & 229 & Tkach et al., 2000a \\
\hline Plagiorchis eleganse & AF151911 & 1,263 & 230 & Tkach et al., 2000b \\
\hline P. koreanus & AF151930 & 1,254 & 230 & Tkach et al., 2000ab, 2001 \\
\hline P. muelleri & AF184250 & 1,254 & 230 & Tkach et al., 2000b \\
\hline P. muris & AF096222 ${ }^{a)}$ & 309 & 309 & Present paper \\
\hline P. vespertilionis & AF151931 & 1,254 & 230 & Tkach et al., 2000ab, 2001 \\
\hline Skrjabinoeces similis & AY222279 & 1,255 & 232 & Olson et al., 2003 \\
\hline
\end{tabular}

a) Sequences generated as part of the current study.

b) Aligned sequence length indicates 28S D1 domain rDNA sequence from 28S rDNA region.

Table 2. Plagiorchiidae species used in this study, GenBank accession numbers for corresponding sequences, sequence lengths for the mtCOI gene

\begin{tabular}{|c|c|c|c|c|}
\hline Species & $\begin{array}{c}\text { GenBank } \\
\text { No. }\end{array}$ & $\begin{array}{c}\text { Sequence } \\
\text { length (bp) }\end{array}$ & $\begin{array}{l}\text { Aligned sequence } \\
\text { length }(b p)\end{array}$ & Reference \\
\hline Glypthelmins californiensis & AY278058 & 381 & 381 & - \\
\hline G. facioi & AY278053 & 383 & 383 & - \\
\hline G. hyloreus & AY278059 & 381 & 381 & - \\
\hline G. quieta & AY278056 & 381 & 381 & - \\
\hline G. tuxtlasensis & AY278054 & 381 & 381 & - \\
\hline Plagiorchis muris & AF096236 ${ }^{a)}$ & 443 & 397 & Present paper \\
\hline
\end{tabular}

a) Sequences generated as part of the current study.

other Plagiorchis species (Fig. 1). The mtCOI tree of $P$. muris was in the separate clade with genus Glypthelmins (Fig. 2).

We found sequence variability in both the $28 \mathrm{~S}$ rDNA and mtCOI region of the family Plagiorchiidae, but the 28S D1 rDNA region was more conserved than the mtCOI region. With respect to the 28S D1 rDNA region, it is also worth noting that $P$. muris had longer sequences (about 68bp at $5^{\prime}$ end) than other species of the Plagiorchis genus. The phylogenic tree of 


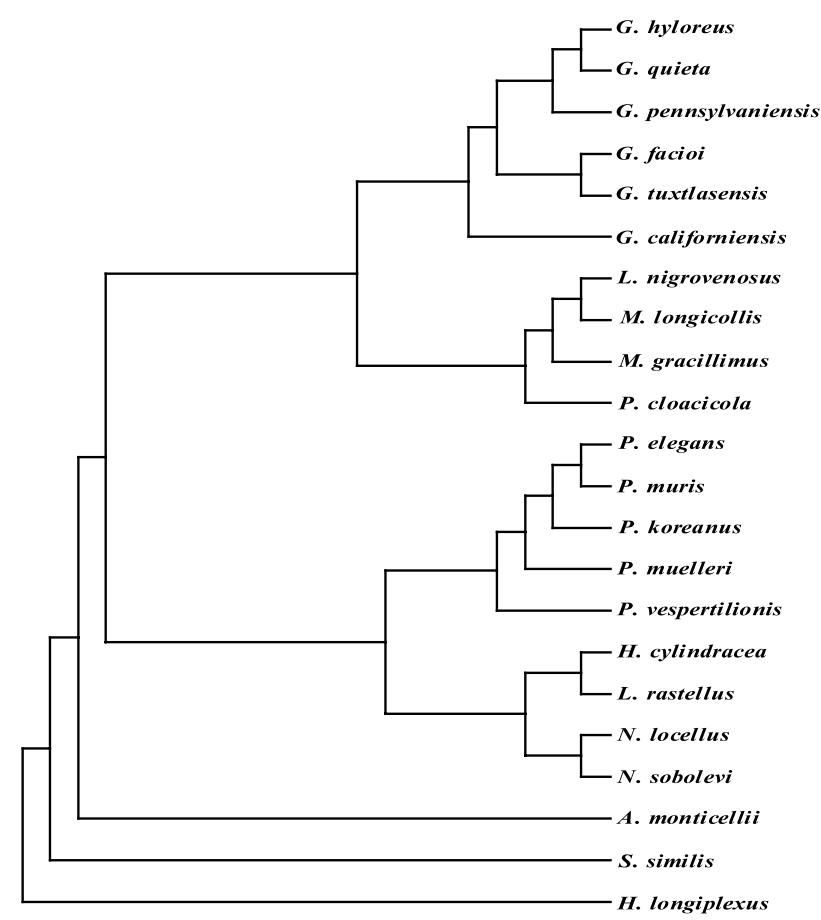

Fig. 1. Phylogenic relationships between the 28S D1 rDNA gene of Plagiorchis muris and other Plagiorchiidae. This parsimonious tree was analyzed by neighbor-joining method using PHYLIP program. G, Glypthelmins; A, Astiotrema; H, Haplometra; L. rastellus, Lecithopyge rastellus; L. nigrovenosus, Leptophallus nigrovenosus; M. longicollis, Macrodera longicollis; N, Neoglyphe; P. cloacicola, Paralepoderma cloacicola; P, Plagiorchis; S, Skrjabinoeces; $H$. longiplexus, Haematoloechus longiplexus.

the family Plagiorchiidae is consistent with a previous molecular analysis of Haematoloechus species and Plagiorchis species using internally transcribed spacer 1 (ITS1), and with large subunit sequence data (Snyder and Tkach, 2001). Tkach et al. (2000a, 2000b, 2001) reported that the suborder Plagiorchiata is composed of two-supported clades, which can be considered superfamilies, namely, Plagiorchioidea including the Plagiorchiidae, and Microphalloidea based on partial lsr DNA sequences. In Plagiorchiidae, a close phylogenic relationship was observed between two Plagiorchis species (P. koreanus, P. vespertilionis), Lecithopyge rastellus, and Haplometra cylindracea. Since there is a little data on mtCOI Plagiorchiidae worms, it is not possible to determine whether P. muris is in the same clade as Glypthelmins spp. However, we infer that P. muris is probably in a separate clade (Fig. 2).

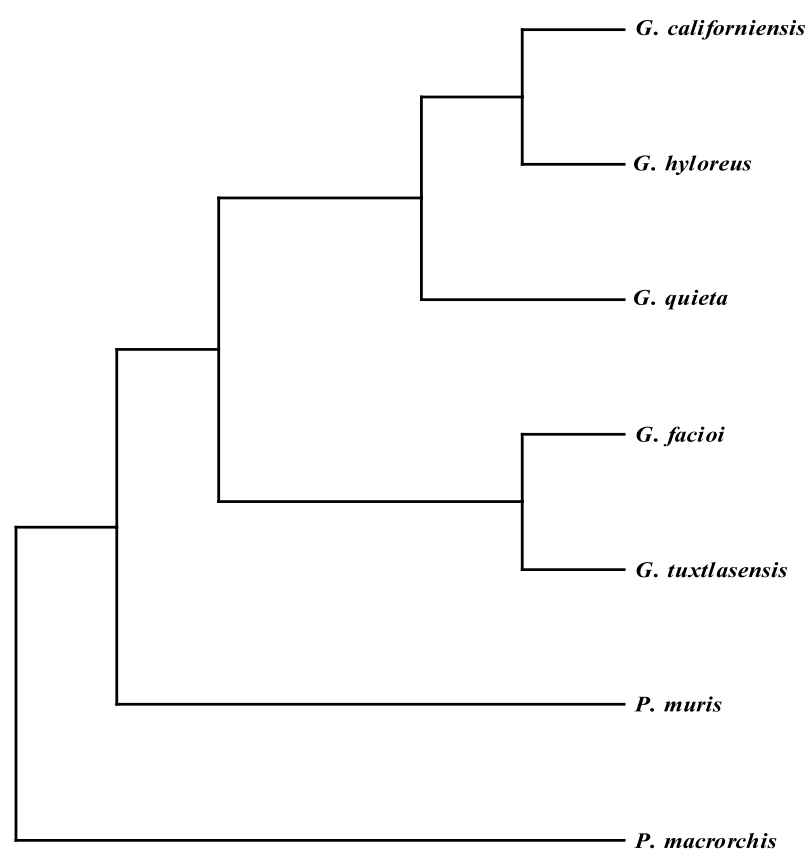

Fig. 2. Phylogenic relationships of the mtCOI gene of Plagiorchis muris with other Plagiorchiidae. This parsimonious tree was analyzed by the neighbor-joining method using PHYLIP program. G, Glypthelmins; P. muris, Plagiorchis muris; P. macrorchis, Paragonimus macrorchis.

The present partial 28S rDNA sequence-base phylogenic analysis of the family Plagiorchiidae including P. muris places the genera Plagiorchis into a welldefined separate clade within the family Plagiorchiidae. The positions of the majority of the taxa of Plagiorchiidae are consistent with the traditional systematic views, the above molecular data also supports the traditional morphology-based conclusion that P. muris belongs to Plagiorchis spp.

\section{REFERENCES}

Chai JY, Lee SH (1991) Intestinal trematodes infecting human in Korea. Southeast Asian J Trop Med Public Health 22: 163-170.

Garey JR, Wolstenholme DR (1989) Platyhelminth mitochondrial DNA: evidence for early evolutionary origin of a tRNA ser AGN that contains a dihydrouridine arm replacement loop, and of serine-specifying AGA and AGG codons. J Mol Evol 28: 374-387.

Hills DM, Mortz C, Marble BK (1996) Molecular Systematics, 2nd ed., Sinauers Assoc. Inc. Sunderland, USA. pp 385-514. 
Hong SJ, Woo HC, Lee SU, Huh S (1999) Infection status of dragonflies with Plagiorchis muris metacercariae in Korea. Korean J Parasitol 37: 65-70.

Kimura M (1980) A simple method for estimating evolutionary rate of base substitutions through comparative studies of nucleotide sequences. J Mol Evol 16: 111-120.

Littlewood DT, Bray RA (2001) Interrelationships of platyhelminthes, London, Tayler \& Francis. U.K. pp 186-193.

Olson PD, Cribb TH, Tkach VV, Bray RA, Littlewood DT (2003) Phylogeny and classification of the Digenea (Platyhelminthes: trematoda). Int J Parasitol 33: 733-755.

Qu LH, Nicoloso M, Bachellerie JP (1988) Phylogenic calibration of the $5^{\prime}$ terminal domain of large rRNA achieved by determining twenty eucaryotic sequences. $J$ Mol Evol 28: 113-124.

Seo BS, Cho SY, Hong ST, Hong ST, Hong SJ, Lee SH (1981) Studies on parasitic helminths of Korea. V. Survey on intestinal trematodes of house rats. Korean J Parasitol 19: 131-136.

Snyder SO, Tkach VV (2001) Phylogenic and biogeographi- cal relationships among some holarctic from lung flukes (Digenea: Haematoloechidae). J Parasitol 87: 1433-1440.

Swofford DL, Olsen GJ, Waddell PJ, Hillis DM (1996) Phylogeny inference molecular systematics. 2nd Edition. Hillis DM, Moritz G, Mable BK. Sinauer Associates Sunderland. Massachusetts. pp 407-514.

Tkach V, Grabda-Kazubska, B, Swiderski Z (2001) Systematic position and phylogenic relationships of the family Omphalometridae (Digenea, Plagiorchiida) inferred from partial 1srDNA sequences. Int J Parasitol 31: 81-85.

Tkach V, Pawlowski J, Mariaux J (2000a) Phylogenic analysis of the suborder Plagiorchiata (Platyhelminthes, Digenea) based on partial 1 srDNA sequences. Int $J$ Parasitol 30: 83-93.

Tkach V, Pawlowski J, Sharpilo VP (2000b) Molecular and morphological differentiation between species of the Plagiorchis vespertilionis group (Digenea, Plagiorchiidae) occurring in European bats, with a re-description of $P$. vespertilionis (Muller, 1780). Syst Parasitol 47: 9-22. 
